\title{
Effects of Music Therapy on Pain, Discomfort, and Depression for Patients with Leg Fractures
}

\author{
In Sook Kwon, RN, MSN¹, Jungnam Kim, RN, Dr.PH², Kyung Min Park, RN, Dr.PH ${ }^{3}$
}

Purpose. To determine the effects of music therapy on pain, discomfort, and depression for patients with leg fractures.

Methods. Data were collected from 40 patients admitted in an orthopedic surgery care unit. The subjects included 20 intervention group members and 20 control group members. Music therapy was offered to intervention group members once a day for 3 days for 30-60 minutes per day. Pain was measured with a numeric rating scale and by measuring vital signs. Discomfort and depression were measured with self-administered questionnaires.

Results. Patients who received music therapy had a lower degree of pain than patients who did not receive music therapy as measured by the numeric pain score $(p<0.001)$, systolic blood pressure $(p<0.01)$, diastolic blood pressure $(\mathrm{p}<0.001)$, pulse rate $(\mathrm{p}<0.001)$ and respiration $(\mathrm{p}<0.001)$. Patients who were provided with music therapy also had a lower degree of discomfort than patients who were not provided with this therapy $(\mathrm{p}<0.01)$.

Conclusions. These results demonstrate that music therapy is an effective method for decreasing pain and discomfort for patients with leg fractures.

Key Words : Music therapy, Pain, Discomfort, Depression, Patients with leg fractures

\section{INTRODUCTION}

Musculoskeletal trauma occurs frequently compared to other general traumatic injuries caused by accidents (Han \& No, 1991), and many patients with traumatic musculoskeletal injury need surgery. The major symptom of musculoskeletal trauma that influences these patients to seek medical services is pain. Other such symptoms include transformation and paralysis (Korean Orthopedic Association, 1999).

Hong (1989) reported that the more pain the patient feels, and the longer the period of pain, the higher the probability of depression. Turner and Romano (1984) also pointed out that chronic pain may cause depression; their survey showed that $30 \%$ of 40 patients who suffered from chronic pain also suffered from depression. In addition, Kim (1994) found that continuous pain caused by musculoskeletal trauma may result in depression and that the pain may also in turn become worse because of the depression. Moon (1994) also found that the extent of pain is highly related to the rate of dysphoria. Finally, a study done by Chung (1996) on the mutual relation between discomfort and depression of patients with plaster bandages and retractors demonstrated that if physical movement is restricted, this may cause physical 
complications and discomfort, and lead to depression.

Based on these studies, it can be predicted that patients with leg fractures are suffering from pain, discomfort, and depression and that these symptoms are interdependent. Because of this, there is an urgent need for the development of an instantaneous and comprehensive nursing intervention that addresses these symptoms.

Some methods to lessen such pain are cold therapy, skin stimulation, massage, relaxation, and distraction (Park, 2000). Distraction therapy includes rhythmic breathing, guided meditation, music therapy, and other interventions (Kang, 1998). Music therapy is an effective nursing intervention to develop, maintain, and recover physical and emotional health. It uses a psychological approach in order to divert a patient's focus from the injury or the resulting restrictions on the patient's life and to reduce ruminations and flashbacks related to the accident that caused the injury (Lee et al., 2000; Hong, 1987).

Kim (1994) analyzed the effects of music therapy on pain and depression of patients with musculoskeletal trauma. However, that study did not address the interconnections among pain, discomfort, and depression. The current study examines the effects of music therapy for patients with leg fractures on changes in their rates of pain, discomfort, and depression.

\section{METHODS}

This research was a controlled experiment which analyzed whether or not music therapy affects the pain, discomfort, and depression experienced by patients with leg fractures. Forty orthopedic patients in $\mathrm{K}$ university hospital in D city were selected for this study. Selection criteria were patients (a) who were between age 16 and 60 , (b) who had had surgery for a leg fracture more than two weeks prior to the study, (c) whose level of pain was either "feel a bit of pain" or "feel pain," (d) who did not have any other pain from other diseases, (e) who had no speech impediment, (f) who had no hearing impairment, and $(\mathrm{g})$ who enjoyed listening to music. Patients in acute pain might perceive any therapy-especially a noninvasive one-as helpful in relieving their pain, and so all those whose pain level was "feel acute pain" were excluded to avoid biasing the results in favor of music therapy. Patients who had had surgery within the past two weeks were excluded because these patients usually feel acute pain for the first two weeks after surgery.
Twenty of the patients were assigned to the intervention group and 20 to the control group. This was done by pairing the patients by age group, sex, and pain level. The intervention and control group patients were then placed in separate hospital units. A questionnaire was administered to the intervention group members asking about their music preferences. This survey was developed by Hartsock (1982) and later revised by Han (1996) to make it more applicable to Korea. Five questions dealt with the participants' taste in music as well as their preferences for particular singers. The participants selected the following musical genres: ballads (9), sacred music (4), classical music (3), foxtrot music (3), and foreign pop music (2). Music with a fast tempo was excluded because it could affect participants' physiological changes. Cassettes and earphones were offered to the participants, and they were asked to listen to the music 30-60 minutes per day for 3 days. In the mornings patients are frequently examined by doctors, and in the evenings they usually have many visitors. So, mornings and evenings were not used as times for the music therapy so that the results would not be biased by the presence of others in the room. For 3 days, the researcher visited each room and asked participants to select tapes and listen to them. While they were listening, the researcher asked the other patients in the room to remain quiet.

Pain was measured by vital signs, taken while participants were lying down, and with a self-rated pain measurement scale which asked the participants to rate their pain from $0=$ "no pain" to 10 = "acute pain."

A new instrument, developed by Chung (1996), was used to measure discomfort. This instrument was originally developed for the purpose of measuring the discomfort felt by patients with plaster bandages and retractors. It was then revised and new items were added to be used for patients with leg fractures. This revision was done by an orthopedist, an orthopedic head nurse, and two nursing professors. The instrument has a total of 20 questions including 7 addressing physical discomfort, 8 for psychological discomfort, and 5 for environmental discomfort. Each question has a 4-point scale for discomfort level with 4 indicating the most discomfort. So, participants' scores can range from a minimum of 20 to a maximum of 80. Chung (1996) found that this instrument had high reliability with a Cronbach's alpha of 0.78. In this study, Chronbach's alpha was 0.79 for this instrument. 
Degree of depression was measured by Zung's (1965) self-rated Depression Scale which was translated by Shin (1977). This instrument contains 10 positively-worded questions, and 10 negatively-worded questions. For each question, there is a 4-point scale, so the total scores for participants range from a minimum of 20 to a maximum of 80 , with a higher score indicating a higher degree of depression. In Chung's study (1998), this instrument had a Cronbach's alpha of 0.67 , but in the current study, Cronbach's alpha was 0.82 .

The preliminary investigation for this study was conducted July 8-15, 2004. An orthopedic nurse was selected to assist with the research and was trained to use the instruments. First, the researcher visited the persons selected for the experimental and control groups between 4:00 and 6:00 p.m. to explain the purpose of the research and obtain agreement to participate. Then, demographic characteristics, level of pain, vital signs, level of discomfort, and level of depression were measured. Beginning the next day, music therapy was applied to the patients in the experimental group for 30 to $60 \mathrm{~min}$ utes per day for 3 days. The researcher visited each participant and let them select which tapes or cassettes they wanted to listen to. Pain level and vital signs were measured between 5:00 and 6:00 p.m. after the music therapy intervention ended each day, and discomfort and depression were measured after the intervention ended on the third day. Pain level, vital signs, discomfort, and de- pression for the control group were measured at the same times as for the experimental group.

\section{RESULTS}

\section{Homogeneity of experimental and control groups}

The experimental and control groups were homogenous on the dependent variables (Table 1-2) as well as on demographic characteristics (Table 1-1) including sex, age, diagnosis, academic background, religion, marital status, and previous surgery. Seventy-five percent of the participants were male, and $33 \%$ were aged $40-49$. Forty percent of the participants had fractured thighs, $25 \%$ had fractured ankles, $25 \%$ had fractured tibia, and $10 \%$ had fractured pelvises. Seventy-three percent of the participants had education beyond the high school level. Seventy percent of the participants had never had surgery before.

\section{Hypotheses}

Hypothesis 1. After the music therapy intervention, pain level for participants in the experimental group, who had music therapy, will be lower than the pain level of participants in the control group, who did not have music therapy.

Repeated measures ANOVA showed a clear difference between average pain levels for the two groups $(\mathrm{F}=$ $29.89, \mathrm{p}=0.000)$ and within individuals over time $(\mathrm{F}=$

Table 1-1. Homogeneity Test of the General Characteristis

\begin{tabular}{|c|c|c|c|c|c|c|}
\hline & & $\begin{array}{c}\text { Total }(\mathrm{n}=40) \\
\mathrm{n}(\%)\end{array}$ & $\begin{array}{l}\text { Experimental group }(\mathrm{n}=20) \\
\qquad(\mathrm{n} \%)\end{array}$ & $\begin{array}{c}\text { Control group }(\mathrm{n}=20) \\
\mathrm{n}(\%)\end{array}$ & $x^{2}$ & $\mathrm{p}$ \\
\hline \multirow[t]{2}{*}{ Gender } & male & $30(75.0)$ & $15(75.0)$ & $15(75.0)$ & 0.00 & 0.642 \\
\hline & female & $10(25.0)$ & $5(25.0)$ & $5(25.0)$ & & \\
\hline \multirow{5}{*}{ Age } & $<20$ & 5 (12.5) & $2(10.0)$ & $3(15.0)$ & 8.05 & 0.090 \\
\hline & $20-29$ & $4(10.0)$ & $4(20.0)$ & $0(-1$ & & \\
\hline & $30-39$ & $9(22.5)$ & $6(30.0)$ & $3(15.0)$ & & \\
\hline & $40-49$ & 13 (32.5) & $6(30.0)$ & $7(35.0)$ & & \\
\hline & $\geq 50$ & $9(22.5)$ & $2(10.0)$ & $7(35.0)$ & & \\
\hline \multirow[t]{4}{*}{ Diagnosis } & tibia fracture & $10(25.0)$ & $5(25.0)$ & $5(25.0)$ & 1.58 & 0.812 \\
\hline & femur fracture & $16(40.0)$ & $7(35.0)$ & $9(45.0)$ & & \\
\hline & ankle fracture & $10(25.0)$ & $5(25.0)$ & $5(25.0)$ & & \\
\hline & pelvic fracture & $4(10.0)$ & $3(15.0)$ & $1(5.0)$ & & \\
\hline \multirow{3}{*}{\multicolumn{2}{|c|}{$\begin{array}{c}\text { Education elementary school } \\
\text { middle school } \\
\text { above high school }\end{array}$}} & $3(7.5)$ & $0(-1$ & $3(15.0)$ & 3.64 & 0.303 \\
\hline & & $8(20.0)$ & $5(25.0)$ & $3(15.0)$ & & \\
\hline & & $29(72.5)$ & $15(75.0)$ & $14(70.0)$ & & \\
\hline \multirow[t]{2}{*}{ Religion } & No & $16(40.0)$ & $8(40.0)$ & $8(40.0)$ & 0.18 & 0.980 \\
\hline & Yes & $24(60.0)$ & $12(60.0)$ & $12(60.0)$ & & \\
\hline \multirow{2}{*}{ Marital } & status single & $8(20.0)$ & $5(25.0)$ & $3(15.0)$ & 1.79 & 0.409 \\
\hline & married & $32(80.0)$ & $15(75.0)$ & $17(85.0)$ & & \\
\hline \multirow{2}{*}{\multicolumn{2}{|c|}{ Experience of Operation ye }} & $12(30.0)$ & $7(35.0)$ & $5(25.0)$ & 0.47 & 0.366 \\
\hline & & $28(70.0)$ & $13(65.0)$ & $15(75.0)$ & & \\
\hline
\end{tabular}


$152.81, \mathrm{p}=0.000)$. There was also a significant interaction effect between group and time $(\mathrm{F}=23.55, \mathrm{p}=$ 0.000 ). Therefore, hypothesis 1 was supported (Table 2 ). The average pain score for participants in the experimental group decreased from an average of 3.85 before the music therapy intervention to averages of $1.95,1.49$, and 1.19 after the music therapy each consecutive day. In contrast, average pain scores for the control group changed from an initial score of 3.50 to $2.90,2.27$, and 2.38 during the same period of time (Figure 1).

Hypothesis 1-1. After music therapy, systolic blood pressure for the experimental group will be lower than for the control group.

Repeated measures ANOVA showed a clear difference between the averages for the two groups $(\mathrm{F}=10.01, \mathrm{p}=$ $0.003)$ and within individuals over time $(\mathrm{F}=7.58, \mathrm{p}=$ $0.000)$. There was a significant interaction effect between group and time $(\mathrm{F}=5.65, \mathrm{p}=0.001)$. So, hypothesis 1-1 was supported. The average systolic blood pressure reading for participants in the experimental group changed from an initial reading before the music therapy of $123.00 \mathrm{mmHg}$ to readings of $117.50,115.00$, and $116.00 \mathrm{mmHg}$ after the music therapy each consecutive day. The corresponding readings for the control group were an initial average reading of $126.50 \mathrm{mmHg}$ and then readings of $127.50,126.00$, and $125.50 \mathrm{mmHg}$.

Hypothesis 1-2. After music therapy, diastolic blood pressure for the experimental group will be lower than for the control group.

Repeated measures ANOVA showed significant differences between the two groups $(\mathrm{F}=14.21, \mathrm{p}=0.001)$ and within individuals over time $(\mathrm{F}=8.80, \mathrm{p}=0.000)$. There was also a significant interaction effect between group and time $(\mathrm{F}=11.67, \mathrm{p}=0.000)$. Hypothesis $1-2$ was supported. The average diastolic blood pressure reading for participants in the experimental group changed from an initial reading before the music therapy of $82.25 \mathrm{mmHg}$ to readings of $74.00,71.75$, and $72.00 \mathrm{mmHg}$ after the music therapy each consecutive day. Average readings of diastolic blood pressure for the control group changed from an initial reading of $80.50 \mathrm{mmHg}$ to $81.50,80.00$, and $82.50 \mathrm{mmHg}$ during the same period of time.

Hypothesis 1-3. After music therapy, the pulse rate

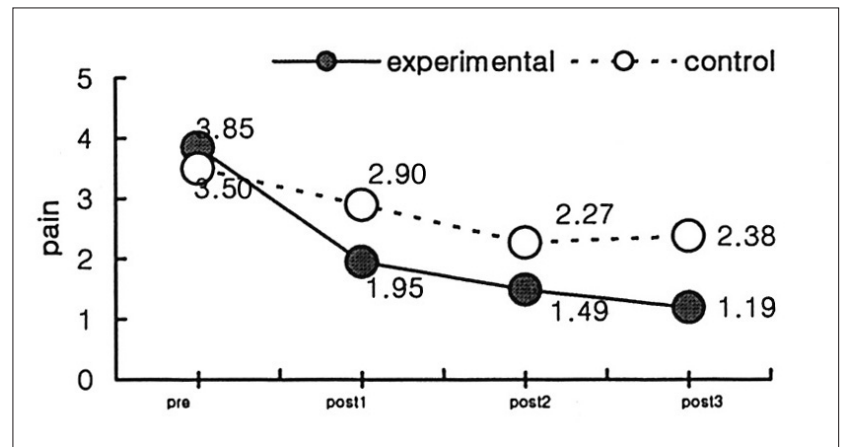

Figure 1. Change in pain scores for experimental and control groups

Table 1 -2. Homogeneity Test for the Dependent Variables

\begin{tabular}{lcrr}
\hline & $\begin{array}{c}\text { Experimental group }(\mathrm{n}=20) \\
\mathrm{M}(\mathrm{SD})\end{array}$ & $\begin{array}{c}\text { Control group }(\mathrm{n}=20) \\
\mathrm{M}(\mathrm{SD})\end{array}$ & $\mathrm{t}$ \\
\hline Pain & $3.85(0.48)$ & $3.50(0.70)$ & 0.58 \\
Systolic pressure & $123.00(11.49)$ & $126.55(16.99)$ & -0.10 \\
Diastolic pressure & $82.25(8.72)$ & $80.50(6.77)$ & 0.58 \\
Pulse (beat/min) & $79.80(12.32)$ & $84.30(12.94)$ & -0.81 \\
Respiration (beat/min) & $19.30(2.38)$ & $18.75(1.11)$ & 1.10 \\
Discomfort & $57.40(9.38)$ & $54.00(5.88)$ & 1.37 \\
Depression & $44.05(7.19)$ & $44.20(5.99)$ & -0.07 \\
\hline
\end{tabular}

Table 2. Difference in Pain Scores between Control and Experimental Groups

\begin{tabular}{lcrrrr}
\hline Source & SS & df & MS & F & \\
\hline Between groups & & & & & \\
$\quad$ Group & 16.51 & 1 & 16.51 & 29.89 & \\
$\quad$ Error & 20.99 & 38 & 0.55 & & \\
Within-subject & & & 30.24 & 152.81 & 0.000 \\
Time & 90.72 & 3 & 4.66 & 23.55 \\
Time $\times$ Group & 13.98 & 114 & 0.19 & 0.000 \\
Error & 22.56 & & \\
\hline
\end{tabular}


for the experimental group will be lower than for the control group.

Repeated Measures ANOVA showed that there were significant differences in pulse rate between the groups $(\mathrm{F}=315.75, \mathrm{p}=0.000)$ and within individuals $(\mathrm{F}=8.20$, $\mathrm{p}=0.000)$ after the therapy. There was also a clear interaction effect between group and time $(\mathrm{F}=12.85, \mathrm{p}=$ $0.000)$. Hypothesis $1-3$ was supported. The average pulse rate for experimental group participants changed from an initial rate of 79.80 before the music therapy to $75.10,75.25$, and 74.45 , after the music therapy each consecutive day. The corresponding average pulse rates for the control group changed from 84.30 initially to 85.70, 84.85, and 84.40.

Hypothesis 1-4. After music therapy, the respiration rate for the experimental group will be lower than for the control group.'

Repeated measures ANOVA showed significant differences between the average breathing rates for the two groups $(\mathrm{F}=6.40, \mathrm{p}=0.021)$ and within individuals $(\mathrm{F}=$ $7.12, \mathrm{p}=0.000)$ after the intervention. There was also a significant interaction effect between group and time ( $F$ $=13.41, \mathrm{p}=0.000)$. So, hypothesis $1-4$ was supported. The average respiration rate for participants in the experimental group changed from 19.30 initially to 18.45 , 18.15 , and 17.05 after the interventions on each consecutive day. The average breathing rate for the control group changed from 18.75 initially to $18.85,18.80$, and 19.05 during the same time period.

Hypothesis 2. After music therapy, the discomfort level for participants in the experimental group will be lower than the discomfort level for participants in the control group.

Repeated measures ANOVA showed no significant difference between average discomfort level for the two groups $(\mathrm{F}=1.83, \mathrm{p}=0.184)$, but there was clear difference within individuals over time $(\mathrm{F}=43.24, \mathrm{p}=0.000)$. There was also a clear interaction effect between group and time $(\mathrm{F}=29.32, \mathrm{p}=0.000)$. So, hypothesis 2 was supported (Table 3). The average discomfort score for participants in the experimental group decreased by 13.56 points from 57.40 before the music therapy to 43.84 after the intervention on the third day. The average discomfort score for the control group decreased only 1.35 points, from 54.00 to 52.65 during the same time period (Figure 2).

Hypothesis 3. After music therapy, levels of depression will be lower for participants in the experimental group than for those in the control group.

Again, repeated measures ANOVA showed no significant difference between average level of depression between the two groups $(\mathrm{F}=0.34, \mathrm{p}=0.558)$, but there was a clear difference within individuals over time $(\mathrm{F}=$ $5.21, \mathrm{p}=0.028)$. There was also no significant interaction between group and time $(\mathrm{F}=0.95, \mathrm{p}=0.334)$. So, hypothesis 3 was rejected (Table 4). Even though there was no statistically significant difference in depression levels between the two groups, the average depression score for participants in the experimental group decreased from 44.05 before music therapy to 40.80 after music therapy, a decrease of 3.25 , while the average depression score for the control group decreased only 1.3, from 44.20 to 42.90 during the same time period. (Figure 3).

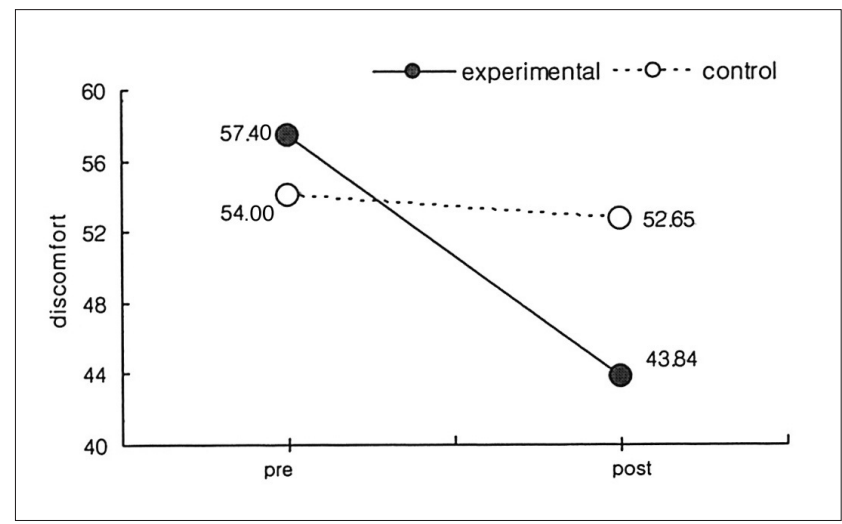

Figure 2. Change in discomfort for control and experimental groups

Table 3. Difference in Discomfort between Control and Experimental Groups

\begin{tabular}{|c|c|c|c|c|c|}
\hline Source & SS & Df & MS & $\mathrm{F}$ & $\mathrm{p}$ \\
\hline \multicolumn{6}{|l|}{ Between groups } \\
\hline Group & 168.20 & 1 & 168.20 & 1.83 & 0.184 \\
\hline Error & 3491.55 & 38 & 91.88 & & \\
\hline \multicolumn{6}{|l|}{ Within-subject } \\
\hline Time & 1170.45 & 1 & 1170.45 & 43.24 & 0.000 \\
\hline Time $\times$ Group & 793.80 & 1 & 793.80 & 29.32 & 0.000 \\
\hline Error & 1028.75 & 38 & 27.07 & & \\
\hline
\end{tabular}


Table 4. Difference in Depression between Control and Experimental Groups

\begin{tabular}{|c|c|c|c|c|c|}
\hline Source & SS & $\mathrm{df}$ & MS & $\mathrm{F}$ & $\mathrm{p}$ \\
\hline \multicolumn{6}{|l|}{ Between groups } \\
\hline Group & 25.31 & 1 & 25.31 & 0.34 & 0.558 \\
\hline Error & 2755.17 & 38 & 72.50 & & \\
\hline \multicolumn{6}{|l|}{ Within-subject } \\
\hline Time & 103.51 & 1 & 103.51 & 5.21 & 0.028 \\
\hline Time $\times$ Group & 19.01 & 1 & 19.01 & 0.95 & 0.334 \\
\hline Error & 753.97 & 38 & 19.84 & & \\
\hline
\end{tabular}

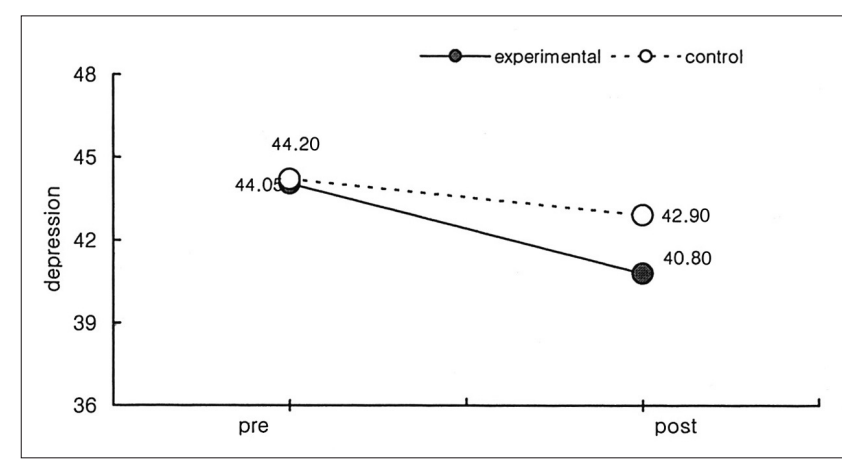

Figure 3. Change in depression for control and experimental groups

\section{DISCUSSION}

This research was performed with patients who had leg fractures. Its purpose was to examine the effects of listening to preferred music on pain, discomfort, and depression in order to develop an immediate, comprehensive nursing intervention for such patients.

The results showed that pain levels for participants who received music therapy were lower than pain levels for participants who did not receive this intervention. According to Luchmann \& Sorensen (1980), heart rate and breathing rate may increase because of the secretion of cortisol which is caused by an excitation of the sympathetic nerve. And, according to gateway control theory, it is possible to decrease discomfort from pain when the brain stem reticulum is activated by listening to music, because a signal to inhibit pain is sent to the spinal cord, and this causes the gateway to close. Music therapy has been shown to be effective in decreasing pain in other research with post-surgery patients (Kang, 1998; Hong, 1989).

In the current study, the average pain score for the experimental group before the music therapy was 3.85 out of 10 , and it decreased to $1.95,1.48$, and 1.19 after the therapy on 3 consecutive days. This was a statistically significant decrease. In comparison, Kim's research (1994) found scores of 2.05, 1.87, and 1.77 after music therapy for the first, second and third days of the intervention. In these studies, the scores for the first day were similar (1.95 and 2.05), but on the second and third days, pain scores declined more rapidly in the current research. This may be because the music therapy was administered for longer periods of time in the current study and that this led to a more rapid decrease in pain.

Although it is difficult to compare the current research with previous studies of music therapy using different patient diagnoses, the results are similar to the results of a number of other studies. In this study, both the patients in the experimental and control groups had vital sign measurements in the normal range, but they had significant differences in systolic blood pressure, diastolic blood pressure, pulse rate, and respiration rate after the music therapy intervention. Kim's study (1994) had similar findings for these indicators except for diastolic blood pressure. Hong's study (1994) also found that patients in experimental and control groups had significant differences in systolic blood pressure, diastolic blood pressure, pulse frequency, and respiration rate after music therapy was applied to the experimental group. However, some previous studies have found different results. Hong (1989) found that music therapy did not decrease abdominal surgery patients ' blood pressure, pulse frequency, or respiration rate, and Kim and Jeon (2000) found that music therapy did not decrease the blood pressure, pulse rate, or respiration rate for patients who had just transferred from surgery to a recovery room. Research done on preoperative patients has also shown effects of music therapy on physiological indicators similar to those of the current study. Augustin and Hains (1996) analyzed the effects of music therapy on patients in the waiting room before surgery and found similar results except for no difference in systolic blood pressure. Another study examined the effects of music therapy on patients waiting for plastic surgery and also found simi- 
lar results except for respiration rate (Updike \& Charles, 1987).

\section{CONCLUSION}

This study demonstrated that music therapy, applied to patients who are more than 2 weeks postoperative after having surgery for leg fractures, can help in reducing subjective pain levels, systolic and diastolic blood pressure, pulse rate, respiration rate, and discomfort. Other studies using music therapy with pre- and postoperative patients with other diagnoses have shown similar results, although some studies have not found changes in the indicators used in this study. More research is needed to further specify at what times during a hospital stay, and for patients with what diagnoses, music therapy is most effective.

\section{References}

Augustin, P., \& Hains, A.A. (1996). Effect of music on ambulatory surgery patient's preoperative anxiety. AORN Journal, 63(4), 750-758.

Chung, Y.S. (1996). A study of the relationship between discomfort and depression in patients with a cast or traction. J Korean Acad Fundam Nurs, 3(2), 171-182.

Hartsock, J. (1982). The Effects of Music Levels on Depression in Orthopedic Patients on Prolonged Bed Rest. Iowa City: The University of Iowa.

Hong, J.J. (1989). Pain, behavior, and depression levels in chronic arthritis patients. Unpublished master's thesis, Hanyang University, Seoul.

Hong, M.S. (1989). The effects of music therapy on patients with postoperative pain. J Korean Acad Adult Nurs, 1, 57-71.

Hong, S.T. (1994). The effects of music therapy on vital sign changes of operational patients. J Korean Acad Nurs, 24(3), 377-388.

Kang, H.Y. (1998). The effect of music therapy on anxiety and pain in dental patients. J Korean Acad Soc Nurs Educ, 4(2), 147158.

Kim, J.A. (1994). Effects of music therapy on pain and depression of musculoskeletal trauma patients. J Korean Rheum Hea, 1(1), 48-70.

Kim, S.J., \& Jeon, E.H. (2000). The effects of music therapy on recovery of consciousness and vital signs in postoperative patients in the recovery room. J of Korean Acad Fundam Nurs, $7(2), 222-238$.

Kim, S.Y.J., \& Han, K.S. (1996). The effect of music therapy on anxiety in neurotic patients. J Korean Acad Nurs, 26(4), 889901.

Korean Orthopaedic Association. (1999). The Medical Aspects of Orthopaedics. Seoul: Choisinuihaksa.

Lee, E.J. (1995). A study of perceived discomfort in patients following cardiac catheterization. J Korean Acad Nurs, 25(1), 124140.

Lee, K.S., Ha, Y.S., Kim, M.J., No, C.H., Yang, S., \& Lee, J.S. (2000). Psychiatric Mental Health Nursing. Seoul: Hyunmoonsa.

Luckmann, J., \& Sorensen, K.C. (1980). Medical Surgical Nursing (Vol. 1). Philadelphia: Saunders.

Moon, M.S. (1994). A study of pain, discomfort, depression and coping patterns in chronic arthritis patients. J Korean Rheum Hea, 1(1), 71-87.

Park, J.S. (2000). Literature review of nonpharmacologic pain management and pain management programs. Keimyung J Nursing Science, 9(1), 119-132.

Park, Y., \& Hong, M.S. (2003). The effects of music therapy on the reduction of anxiety and discomfort on patients undergoing gastrofibroscopy. J Korean Acad Adult Nurs, 15(1), 67-77.

Shin, S.C. (1977). A self-rating depression scale for psychiatric outpatients (II). J of Chung Nam University, 4(1), 84-89.

Turner, J.A., \& Romano, J.M. (1984). Self-oreport screening measures for depression in chronic pain patients. J Clin Psychol, 40, 909.

Updike, P.A., \& Charles, D.M. (1987). Physiological and emotional responses to taped music programs for preoperative patients awaiting plastic surgery. Ann Plast Surg, 19(1), 29-33.

Wolff, L.M. (1983). Fundamentals of Nursing (7th ed.). Philadelphia: Lippincott.

Zung, W.K. (1965). A self-rating depression scale. Arch Gen Psychiatry, 12, 63-75. 